\title{
Fernando Charry Lara y la RECEPCIÓN DEL SURREALISMO EN Colombia*
}

\author{
Fernando Charry Lara and the \\ Reception of Surrealism in Colombia
}

Janeth Alejandra García Herrera ${ }^{1}$

* Artículo derivado del trabajo de investigación: El Espejo invertido: una lectura del surrealismo a través de Fernando Charry Lara y Emilio Adolfo Westphalen.

Cómo citar este artículo: García Herrera, J. A. (2020). Fernando Charry Lara y la recepción del surrealismo en Colombia. Estudios de Literatura Colombiana 47, pp. 37-54. DOI: https://doi.org/10.17533/udea.elc.n47a02

1 https://orcid.org/0000-0001-5197-9616 jaagarciahe@unal.edu.co

Universidad Nacional de Colombia, Colombia

Editores: Andrés Vergara Aguirre, Christian Benavides Martínez, Valentina Noreña Gómez

Recibido: 15.02 .2019

Aprobado: 09.05.2020

Publicado: 23.06.2020

Copyright: $\odot 2020$ Estudios de Literatura Colombiana. Este es un artículo de acceso abierto distribuido bajo los términos de la Licencia Creative Commons AtribuciónNo comercial - Compartir igual 4.0 Internacional
Resumen: este artículo estudia la recepción del surrealismo en Colombia a partir de un caso paradigmático como el del poeta Fernando Charry Lara. Aunque la crítica ha intentado establecer la influencia del movimiento francés en su obra poética, su lectura del surrealismo no ha sido lo suficientemente estudiada en su obra crítica. Por esto, primero se reconstruye el campo cultural que sirvió de telón de fondo para la recepción de las vanguardias en Colombia. Luego, se analizan cronológicamente varios artículos del autor, con el fin de descubrir las particularidades de este proceso. El análisis permite evidenciar un cambio en su actitud no solo hacia el movimiento francés, sino en su concepción de la poesía.

Palabras clave: Surrealismo; Poesía latinoamericana; Fernando Charry Lara.

Abstract: This article studies the reception of Surrealism in Colombia taking Fernando Charry Lara as a representative case. Although previous studies have tried to establish the influence of the French movement on his poetical work, his reading of surrealism has not been sufficiently studied in his critical work. For this reason, the cultural field that served as a backdrop for the reception of avant-garde movements in Colombia is first reconstructed. Then, several articles of the author are analyzed chronologically, in order to reconstruct the particularities of this process. This analysis shows a change in his attitude not only towards the French movement, but also in his conception of poetry.

Keywords: Surrealism; Latin-American poetry; Fernando Charry Lara. 
El surrealismo, entendido como cosmovisión a través del ejercicio teórico de sus pensadores, encabezados por André Breton, fue un campo fértil para las semillas de la poesía moderna en Hispanoamérica durante el siglo xx. Más que como poeta, Breton fue leído en Hispanoamérica como teórico, filósofo o profeta. Su doctrina sobre la unión de arte y vida junto a su defensa radical del arte y de la poesía en una época convulsa histórica tanto como socialmente sirvió de soporte y aliento para muchos artistas alrededor del mundo. A pesar de las difíciles condiciones de circulación que enunciaremos a continuación, las ideas de Breton logran gran difusión y aceptación en los poetas colombianos, en este caso, en Fernando Charry Lara.

A través de la lectura y puesta en diálogo de los textos críticos de prensa y escritos de los principales actores de la época, el presente artículo aborda la complejidad de la circulación de las ideas de un movimiento como el surrealismo y las condiciones que permitieron o dificultaron su apropiación en un campo de recepción diferente al de producción, en este caso. La recepción del surrealismo - y en general de los movimientos de vanguardia - en Colombia fue un proceso lento y difícil que duró varias décadas, pues tuvo que superar obstáculos sociales e institucionales que retardaron su asimilación e hicieron necesaria la intervención de críticos como Octavio Paz, Luis Cernuda o Luis Cardoza y Aragón para que pusieran en evidencia su importancia.

La primera mitad del siglo xx no fue fácil para el país, ya que iniciaría con la Guerra de los Mil Días y la separación de Panamá, y terminaría en el Bogotazo y la formación de las guerrillas. En el Manual de Historia de Colombia, Jesús Bejarano (1982) afirma que la Guerra de los Mil Días “dejaba, pues, como saldo, la paralización de la agricultura, el rompimiento del comercio y de las comunicaciones y un desvertebramiento total de la circulación monetaria y de la esfera financiera" (p. 19). Por su parte, Armando Romero (1985), en Las palabras están en situación, asegura que a principios del siglo xx hubo una fuerte "escasez alimenticia [y un] alto porcentaje de analfabetismo, con sus consecuencias lógicas de inmovilidad social y descontrol individual, lo que derivaba en un lamentable cuadro de autodestrucción por alcoholismo y violencia” (p. 38).

La represión de los movimientos obreros en la década de los veinte, cuyo epítome fue sin duda la masacre de las bananeras, y la aguda crisis económica en la que el país estaba sumido crearon la necesidad urgente de un cambio social. Al respecto, Jaime Jaramillo Uribe (1982) comenta que 
[...] la gran depresión de 1930 puso fin a la sucesión de gobiernos conservadores que se había iniciado en 1886 y dio comienzo a gobiernos liberales que se caracterizaron por su impulso reformista. En contraste con la clase dirigente de las décadas anteriores, [la] nueva élite liberal poseía una mentalidad modernizadora (p. 328).

Como resultado, en 1934, con el ascenso al poder del candidato liberal Alfonso López Pumarejo (1934-1938 y 1942-1945), se iniciaría un proyecto de "revolución en marcha" que buscaba mejorar las condiciones de vida de los colombianos a través de diferentes reformas. Sin embargo, acota Armando Romero (1985), "ese intento de llevar a Colombia al capitalismo moderno muere en manos de los terratenientes más poderosos del país, y en manos del mismo gobierno y sus protegidos" (p. 60). Las oscilantes condiciones económicas del país y la lucha de la oligarquía por el poder, que generó una constante y creciente ola de violencia, dificultarían la modernización social y cultural, que estaría marcada, como la historia misma del país, por una serie de avances y retrocesos continuos.

Puede decirse que la recepción de la vanguardia en Colombia tuvo dos momentos: uno con la generación de "Los Nuevos", hacia 1920, y otra con el grupo Mito, hacia 1940, pasando por una etapa de transición con los piedracielistas. Estos momentos se analizarán a continuación para comprender las condiciones que el campo literario colombiano impuso para la asimilación del movimiento surrealista y el papel del movimiento bretoniano en la modernización de la poesía colombiana.

\section{Del Centenario a Mito}

La década de los veinte convocó a Los Nuevos, una generación que estaba "insatisfecha con la política y la literatura que dominaban la época” encarnadas en la generación anterior, la del Centenario (Ardila Ariza, 2013, p. 11). La valoración positiva de "lo nuevo" fue el rasgo común de este grupo de jóvenes interesados en el debate de las ideas y que, con este ánimo, intentaron "adecuar su poética a las búsquedas más consecuentes con la identidad política de sus partidos" (p. 13). Hubo gran actividad en periódicos y revistas que difundieron los manifiestos vanguardistas y la actualidad literaria internacional. Sin embargo, el grupo carecía de un "principio o una búsqueda estética que los uniera” (p. 284), e incluso sus posiciones llegaban a ser totalmente opuestas. Quizá los polos de apreciación estética del movimiento, entre los que oscilaban las demás posiciones, eran Luis Tejada y Rafael Maya. 
En 1923, Luis Tejada (1977) critica la actitud reaccionaria de un país al que considera "esencialmente conservador en todos los aspectos de su vida, pero singularmente en lo que se refiere a la literatura", un país que "cree que la circunspección clásica, que el encerrarse dentro de ciertos moldes trasegados y consagrados es una postura elegante; [aunque] en todo caso, es también una postura perfectamente imbécil y estéril" (p. 158). La postura de Tejada es cercana a la de Mariátegui en Perú, pues el deseo de revolucionar la lírica va unido a un deseo de renovación política, acompañado siempre por una constante actualización y análisis de los movimientos culturales alrededor del mundo. Por eso, Tejada se queja de que, en Colombia, "todas las inquietudes de los últimos veinte años les merecen, a los que por casualidad tienen noticias de ellas, cuando más una sonrisa, pero nunca un gesto de comprensión ni mucho menos una simpatía estimulante" (p. 158). Tejada sería un tenaz promotor de la naciente poesía de Luis Vidales, pues la consideraba un camino a seguir para fundar una nueva poesía colombiana más a tono con la modernidad europea de la vanguardia.

En el extremo opuesto, Rafael Maya defiende los bastiones del orden y equilibrio clasicista y los valores intemporales del arte y el espíritu, y critica duramente el arte de los movimientos contemporáneos, al cual considera "transitorio, ostentoso y banal, porque su radical rompimiento con el pasado acorta su proyección sobre el porvenir" (citado en Jiménez, 1992, p. 178). El problema del arte de la posguerra es que se aparta de la tradición, de los temas intemporales por excelencia: la naturaleza y lo sublime, es decir, lo bello, lo bueno y lo verdadero. "Sus fuentes de inspiración no son ni la reflexión metafísica, ni el espectáculo del universo, ni los anhelos sobrenaturales del alma, sino la tenebrosa subconciencia y los sótanos de la personalidad, donde se amontonan los instintos y perversiones del hombre no redimido por los poderes del espíritu” (p. 178). Según David Jiménez (1992), "de Maya podría decirse algo semejante a lo que él escribió de Antonio Gómez Restrepo: que supo escuchar el canto de las sirenas modernas, pero bien amarrado al mástil de la cultura clásica [...] que comprendía dos vertientes fundamentales: el mundo clásico antiguo y la tradición española” (p. 201).

La abismal diferencia impidió que se concretara un proyecto de renovación y modernización de la poesía. Según Jineth Ardila Ariza (2013), les faltó unidad, pues "los grupos se disolvían tras sus primeros enfrentamientos contra la generación que los precedía, porque lo único que los unía era la idea de ese enfrentamiento”(p. 14). Además, 
[...] la crítica tradicionalista se encargó de separarlos aún más, tanto la que aprobaba y celebraba la obra de los menos radicales como la que rechazaba al unísono la de los más novedosos: así, Rafael Maya fue rápidamente acogido dentro de la tradición poética del país, mientras Luis Vidales no fue nunca aceptado (p. I4).

La muerte temprana de Luis Tejada y la exclusión institucional de Luis Vidales truncaron el proyecto, apenas esbozado, de modernización literaria en su extremo más audaz. De hecho, "es tan abrupta la desaparición del grupo, que da la impresión de que este proyecto cultural no hubiera terminado de realizarse y hubiera sido abandonado por los jóvenes" (Ardila Ariza, 2013, p. 284). La fuerte tradición humanista conservadora, clasicista e hispanófila, mantuvo a salvo el predominio, al menos a nivel institucional, del orden y la claridad en la literatura colombiana gracias a entidades como la Academia de la Lengua, que "divulgaron a los representantes de la tendencia poética favorecida y realizaron una tarea crítica de demolición en contra de las corrientes literarias modernizantes” (Jiménez, 2002, p. 37).

Años más tarde, hacia 1935, la publicación de un grupo de libros de poesía con características comunes había dado paso a la aparición de un nuevo grupo: "Piedra y Cielo", como se conocerían después. Ante la novedad de esta poesía, los críticos se quejaban de la dificultad y el hermetismo de los nuevos poetas, $\mathrm{y}$ "muchos confundieron lo difícil con lo vanguardista y durante un tiempo se consideró a este grupo de poetas como un movimiento de vanguardia" (p. 105). Sin embargo, el líder del movimiento, Eduardo Carranza, insistió en que Piedra y Cielo era un "movimiento de restauración hispánica y neoclásica, directamente entroncada con la poesía española, en especial con los intentos peninsulares de revaloración del gongorismo”, o más específicamente, con Juan Ramón Jiménez y la generación del 27 (Jiménez, 2002, p. 105).

No obstante, aunque la regresión a una tradición "hispánica y neoclásica” está lejos de ser una tendencia modernizante de la poesía, Rafael Gutiérrez Girardot (2011) hace notar que, en el ambiente literario cargado de didactismo y grandilocuencia,

[...] la profesión de fe por Juan Ramón Jiménez era, en efecto, "revolucionaria": postulaba la figura del poeta dedicado íntegramente a la poesía y con ello rechazaba implícitamente la figura del poeta político o del tolerado poeta posromántico o bohemio; postulaba, consecuentemente, una poesía 'pura' en el sentido de no retórica y en último término declaraba que la poesía política-retórica había perdido toda su vigencia, que se había quedado rezagada (p. 100). 
A pesar de su defensa de la pureza poética y de su devoción por Juan Ramón Jiménez y la generación del 27, el movimiento piedracielista careció de carácter turbulento y tampoco provocó comentarios críticos concienzudos sobre la naturaleza y función de su poesía. De acuerdo con Gutiérrez Girardot (2011), el "piedracielismo" colombiano fue "vanguardia" en la Colombia conservadora (p. 109), porque abrieron el camino para el juego verbal, la renovación del lenguaje y la experimentación metafórica, al tiempo que proclamaron la autonomía de la poesía, lograron limpiarla de funciones ancilares y de una claridad esclavizante que la mantenía petrificada.

Sin embargo, al igual que sus predecesores, carecían de esa característica necesaria para modernizar la lírica nacional que Luis Tejada (1977) había reclamado en 1923: "adoptar una actitud de simpatía activa incorporándonos a la agitada vida que transcurre fuera, uniéndonos por algún hilo vital al mundo conmovido y maravilloso que va en marcha hacia adelante"(p.158). Esta sería la principal objeción de los contemporáneos y la generación posterior a Piedra y cielo. En 1941, en el marco de la polémica sobre Guillermo Valencia que despertó Eduardo Carranza, ${ }^{1}$ Antonio García (1941) escribiría sobre el movimiento piedracielista lo siguiente:

[...] lo grave del fenómeno está en que ha cambiado la época y nuestra poesía permanece sin cambios substanciales, de espaldas al mundo sin recoger ninguna de las grandes angustias que pesan en la sensibilidad colombiana. Nuestra poesía desprecia al pueblo y al hombre para no abandonar su carácter de "pura", siguiendo los rumbos de la poesía hiperestésica de la ex-metrópoli. [...] Que la función del poeta es 'cantar sin compromisos', convenido: pero el poeta debe perfeccionarse como ser receptor para que no haga el pobre papel narcisista de considerar el mundo como un simple reflejo suyo (p. 2).

La época de l'art pour l'art ya había pasado, y las angustiosas circunstancias del país y del mundo reclamaban una postura del poeta, que no le exigía un arte comprometido, pero sí al menos una poesía coherente, ya no de juego verbal, sino época. Para más detalles, en Poesía y Canon de David Jiménez, el capítulo III, "Piedra y Cielo: un campo de lucha por el poder canónico”, describe las diferentes posiciones y el detalle del desarrollo de la polémica. 
de experiencia humana. La poesía no podía seguir cantando lo bueno, lo bello y lo verdadero, ni tampoco la pureza y la riqueza del lenguaje, sino que necesitaba estar más íntimamente ligada a la vida de los sujetos. A pesar de que el grupo de Piedra y Cielo dominó la escena cultural por más de una década, debido a la ausencia de reflexión crítica no solo sobre los fenómenos mundiales, sino también sobre sus propios textos, "la fuerza intelectual desplegada por [la generación piedracielista], su capacidad para transformar ideas, concepciones estéticas, formas, es decir, la vida espiritual de la cultura, fue mucho menor que su poderío como ejército de invasión en el campo institucional" (Jiménez, 2002, p. 141).

A finales de la década del cuarenta, entonces, la discusión sobre la vanguardia estaba más que presente, así como "la imperiosa necesidad de superar la influencia de 'Piedra y Cielo' seguía siendo una consigna válida en 1949 y es la razón por la cual se celebra la novedad vanguardista" (p. 178). En un artículo de 1944, sobre el recién publicado número de los cuadernos de Cántico con la selección de poemas de Fernando Charry Lara, Andrés Holguín (1944) hace una breve anotación sobre el origen y fuente de la poesía:

La poesía sube de aquellas fuerzas que arrastran las almas, las vibraciones que - casi imperceptibles - sacuden poderosamente el espíritu y, empleándolos, nace de aquellos signos y aquellos llamamientos que desecha la razón y que, en cambio, asimilan el sueño, la intuición, el sentido (p. r).

La concepción de la poesía de Holguín implica cierto irracionalismo, el descubrimiento de las potencias ocultas del hombre reprimidas en la intuición y el sueño por la razón. La poesía no nace de las aguas tranquilas del orden clásico, sino de fuerzas y vibraciones que arrastran y sacuden al ser humano internamente. La "temerosa subconciencia y los sótanos de la personalidad”, que tanto aterraban a Maya, se han convertido en el tema y medida de la poesía moderna. No son ya los valores intemporales de lo bello y lo bueno, sino el individuo, en toda su complejidad y profundidad, el que ocupa el centro de la poesía.

Holguín (1944), antes de comentar la poesía de Charry Lara, hace un breve balance de su generación, y afirma que esta 
[...] representa una notable reacción contra el movimiento piedracielista aunque, por otra parte, haya captado y asimilado los elementos de belleza y de renovación estética que aquel puso en vigencia. Esta reacción se aprecia en el desafecto por la extremada gracia verbal [...]. Creo que el último grupo poético, posterior a "Piedra y Cielo", aspira a una verdad más desnuda, a una poesía más humana y experimental, a un arte más depurado (p. I).

Los cuadernícolas, como se les llamóluego a los fundadores de Cántico, quienes también fueron en su mayoría integrantes del grupo Mito, aprenden el potencial estético del lenguaje de sus predecesores, pero ponen en el centro la experiencia humana como cerco y medida de la expresión. Por eso, "en relación con el movimiento piedracielista, el último grupo ha adoptado una actitud más introspectiva”, tienen una "hondura interior, que le resta quizá brillantez formal, la tiñe de melancolía, la ensombrece de opacas ensoñaciones, la penumbra de presencias misteriosas” (p. 1). Para tomar distancia tanto del didactismo horaciano de sus predecesores decimonónicos como del juego verbal de los piedracielistas, los cuadernícolas escribieron una poesía más personal, se refugiaron en los "sótanos de su personalidad" y cantaron su desdicha. Luego de la Primera Guerra Mundial y justo en medio de la Segunda, los poetas de esta generación no pueden seguir con la claridad celebratoria de sus predecesores: el futuro es desolador e incierto a nivel nacional e internacional, de ahí su melancolía y su inclinación por la opacidad y el misterio.

La actitud de los poetas de la generación posterior a Piedra y Cielo fue la de alumnos frente a maestros, ya que recibieron lecciones sobre la poesía en el aspecto formal. No obstante, ante la ausencia de un asidero espiritual y ético que las circunstancias sociales y el momento histórico (Bogotazo, Segunda Guerra Mundial, la Violencia...) les demandaban, tuvieron que buscar en los poetas pasados y contemporáneos el modo de suplir esta carencia.La búsqueda del restablecimiento del lazo entre la poesía y la experiencia vital del hombre contemporáneo no se manifiesta tanto en la aparición de libros con un lenguaje y forma radicalmente distintos, con irracionalismo radical o aniquilamiento del lenguaje, sino que se convierte en toda una reevaluación de la tradición y los modelos literarios hasta entonces preeminentes a través de una constante actividad crítica y teórica: "trataron de modelarse a imagen del poeta docto, crítico y autocrítico, consciente del proceso creativo, en diálogo abierto con la gran poesía de su propia época y del pasado" (Jiménez, 2002, p. 155). 
Esta actitud se desarrollaría de manera plena con la fundación de la revista Mito, que se caracterizó no solo por su actividad crítica, sino de traducción y difusión de textos literarios y de otras áreas como la pintura o la política. Charry Lara (2012), en una mirada retrospectiva en 1979 sobre la actitud de su generación, afirma:

[...] un exceso de gracias, finuras y preciosismos encontrábamos en nuestros predecesores y queríamos rechazar su ascendiente dando una nota de gobernada pasión. [...] Y otros poetas, en quienes se entendía así mismo una más honda vibración con el mundo contemporáneo, como Neruda, Vallejo, Huidobro, Cernuda y Aleixandre, pudieron apreciarse en sus aspectos más esenciales.

Nos atraía cuanto se refiriese al romanticismo alemán y a su influjo en la lírica moderna. Queríamos para nuestra propia poesía un acento fundamentalmente expresivo, más que esbelto, revelador del hombre. [...] Comenzaban a interesarnos menos las tendencias preocupadas por el brillo de la palabra y nos atraían en cambio, sin caer en un franco irracionalismo, las zonas nocturnas de la poesía surrealista. Queríamos conciliar la vigilia y el sueño, la conciencia y el delirio (pp. 310-3II).

Antes que buscar un nuevo lenguaje, más esbelto o depurado, se trataba de un problema expresivo, de encontrar voces que pudieran cantar el drama humano en toda su complejidad. Por eso el interés por encontrar poetas homólogos en Hispanoamérica que sintieran y cantaran el movimiento del mundo contemporáneo, como Neruda y Vallejo, y su inclinación por el Romanticismo alemán, por el surrealismo en tanto heredero de este último. Así que, en esta época, "Rilke, Eliot, Valéry, Saint-John Perse, Neruda, Machado, Aleixandre, Cernuda fueron autores cuyas obras, muy leídas y comentadas en revistas y suplementos del país, permitieron plantear la cuestión de la poesía moderna y sus diferentes significados"(Jiménez, 2002, p. 178). La labor poética de la generación de Mito se movía en dos frentes: la escritura ensayística de textos críticos sobre poetas de todo el mundo y sobre las obras de sus colegas, y la escritura poética propiamente dicha, lo que permite un proceso de circulación de las ideas mucho más dinámico.

Los poetas fundadores de Cántico y de Mito tomaron del surrealismo "aquello que implica una actitud crítica frente a la vida y una amplia libertad para la imaginación", aun cuando "la ortodoxia surrealista, su dogma del automatismo psíquico y su revolución social impregnada de marxismo, nunca entrarían en la poesía colombiana" (Romero, 1985, p. 114). La lectura del surrealismo jugó un papel importante como asidero espiritual, entendido siempre como continuación contemporánea de la 
búsqueda romántica. En la transformación o modernización de la poesía colombiana "no hay, pues, un salto hacia la negación o hacia la rebelión contra todo un sistema establecido sino un penetrar lentamente en el recinto de la poesía colombiana, a fin de tratar de renovar las cosas desde adentro, sin 'cadáveres exquisitos”' (p. 57).

En este "penetrar lento en el recinto de la poesía colombiana”, Fernando Charry Lara busca entre sus contemporáneos el sustento ético y espiritual que ponga su poesía a tono con las preocupaciones del hombre moderno. Como resultado, encuentra en Luis Cernuda y en Vicente Aleixandre no solo la amistad poética, sino la filiación espiritual anhelada. Charry Lara escribió numerosos ensayos y reseñas sobre poetas modernos alrededor del mundo, pero es la lectura y casi inmediata simpatía por los dos poetas españoles la que marcaría su propio desarrollo como poeta, además de la consagración de varios estudios y una devota amistad (epistolar en ambos casos) a lo largo de toda su vida.

"Luis Cernuda y Vicente Aleixandre, quienes no compartieron la afición al formalismo y al juego ingenioso que dañó buena parte de la obra de la Generación de 1927" (Charry Lara, 2012, p. 514), "representaban lo contrario de la oratoria y de la declamación que ya empezaba a detestar en mucha poesía colombiana, hispanoamericana, española” (Charry Lara, 1986, p. 115). Los diferentes estudios y revisiones que Charry Lara hace sobre la poesía y la crítica de los poetas españoles, que van desde 1940 hasta la década de los ochenta, muestran variaciones en sus lecturas, en su concepción de la poesía, la tradición y, sobre todo, en el papel del surrealismo como sustento ético de su propia poesía. Es así que la lenta recepción de los postulados surrealistas en el país, y que se da en Charry Lara a través del tamiz que los españoles y poetas de otras latitudes como Octavio Paz le proporcionaron, será comprobable a través del análisis cronológico de algunos textos críticos de Charry Lara que iniciaremos a continuación.

\section{Charry Lara y el aprendizaje surrealista}

Uno de los primeros artículos que publica Charry Lara (2012) en la Revista de las Indias, a finales de 1940, se titula "La poesía de Luis Cernuda", en el cual hace un breve comentario sobre el significado de la obra del poeta español en su tiempo, a quien considera "el más claro tipo del hombre sometido a su destino de poeta" (p. 19). Su poesía, dice Charry Lara, es eterna porque trata problemas humanos y universales y, 
aunque es imposible clasificarlo en alguna de las tendencias contemporáneas, se podría definir como un "romántico desencadenado" (p. 20). En un ensayo posterior de 1948, Charry Lara (2012) sigue identificando en Cernuda una "raíz romántica" y dedica un estudio a ponerlo en relación con Bécquer, Baudelaire y los románticos alemanes, pues la poesía del vate español, "permanente en la agonía de cada verso, la sitúa entre las mejor logradas manifestaciones del moderno romanticismo" (p. 66). Charry Lara identifica en Cernuda un Romanticismo que corresponde sobre todo a la honda descripción de un drama humano, porque "nunca como en la edad contemporánea ha sido más agudo el sentimiento de soledad en un espíritu poético” (p. 66). Ese drama humano corresponde a la separación de la realidad y el deseo, dualidad que titula la obra poética del autor español. La separación del ideal del poeta de una realidad que no se ajusta ni en sombras a ese deseo es la dualidad fundamental que el arte romántico explora y profundiza, y su mayor aspiración es la superación de esta escisión y el retorno a un estado de unidad del yo y el mundo. En 1946, Charry Lara publica en la Revista Trimestral de Cultura Moderna de la Universidad Nacional de Colombia un artículo titulado "Vicente Aleixandre y la moderna expresión lírica". En este texto, tras la noticia de la reciente publicación de Sombra del paraíso, hace un recuento de los anteriores libros de Aleixandre y de los cambios que ha venido sufriendo su poética. $\mathrm{Al}$ referirse a los repetidos comentarios que ubican la obra del poeta español dentro de las manifestaciones surrealistas o superrealistas, ${ }^{2}$ Charry Lara (2012) afirma que

[...] el acento romántico de la obra, visible en los temas escogidos, es muy natural dentro del pretendido superrealismo de Aleixandre. Que esta tendencia no es más que un romanticismo exagerado, es una afirmación que, ante demostraciones como las que se ofrecen en esos versos apasionados, hay que aceptar sin reservas (p. $5 \sigma$ ).

[En Espadas como labios] falta la puntuación, se operan diversas transposiciones poéticas y los versos se reúnen en una agrupación caprichosa. Pero hay algo más en el fondo, ¿se cumple realmente la consigna superrealista? Yo me aparto de creerlo así y apenas juzgo que sólo en las libertades del lenguaje reside su adhesión a esa escuela (p. 58 ).

El acento romántico tanto de Cernuda como de Aleixandre es visible en la elección de los temas, en la manifestación de una experiencia vital de soledad o desamparo que intuye a común en el español penisular y durante la primera mitad del siglo xx. Actualmente, ha perdido su uso y se prefiere la primera forma. 
través de la poesía la Sombra del paraíso, pero es incapaz de alcanzarlo. La introspección y el habitar los sótanos de la conciencia no conduce a la expresión del sentimiento individual o anecdótico, sino a la participación en un drama universal. Para Charry Lara, la obra de Aleixandre no puede calificarse como surrealista, en especial los últimos libros publicados, porque carece de un elemento esencial: la "entrega al inconsciente". Y aunque reconoce que la experiencia del surrealismo fue valiosa, sobre todo para la escritura de los primeros libros, Aleixandre ha abandonado ya el lenguaje convulso de esos poemas, quizá único rasgo en común con el movimiento, y ha entrado en otra etapa poética.

En estos primeros artículos se nota ya la devoción que profesa el joven poeta hacia sus homólogos españoles y algunos de los rasgos que considera valiosos como la universalidad en la elección de temas y problemas del hombre contemporáneo — del drama humano-, la claridad y concreción de la expresión, la precisión de la palabra, la adecuación entre el lenguaje y la forma del verso con la actitud hacia el mundo, la unión entre poeta y poesía, entre vida y obra. Es un rasgo común en estos ensayos identificar la obra de Cernuda y Aleixandre con una tradición más amplia: el Romanticismo, pero no el anquilosado Romanticismo español, sino la tradición de los ingleses y alemanes que continuó en algunos franceses como Baudelaire y en una figura rara como Bécquer en España. Se trata de "un espíritu [que] intenta librarse de las cosas y aspira a alcanzar una patria infinitamente remota" (Raymond, 2002, p. 35). Charry Lara no se preocupa por establecer la filiación de Aleixandre y Cernuda con las corrientes literarias del momento como el surrealismo. No se desconoce la importancia del movimiento; pero, en este punto, si Aleixandre y Cernuda se han convertido en sus modelos, es por inscribirse en una tradición que obedece a la búsqueda de expresión del hombre moderno y que tiene sus orígenes en el Romanticismo.

Sin embargo, la actitud de Charry Lara hacia la corriente surrealista tiene un cambio significativo sobre todo luego de la lectura de la obra poética y ensayística de Octavio Paz a principios de los años cincuenta. Décadas más tarde,en 1984, en un texto conmemorativo de los setenta años de Octavio Paz, Charry Lara (2012) afirma que

[...] cuando se conmemora este nuevo aniversario es inevitable, para quienes desde acá le han seguido a través de sus libros, aludir a la repercusión que los poemas y ensayos de Octavio Paz han tenido en Colombia. Su ascendiente ha sido considerable a partir de algunos de los poetas que surgieron luego del grupo de 'Piedra y Cielo' y que publicaron sus primeras colecciones al promediar la década de 1940 (p. 513). 
Así lo atestiguan los numerosos ensayos y reseñas en los que sopesa y, en varias ocasiones, suscribe las teorías del poeta mexicano sobre la poesía. En 1951 publica, en El Liberal, un texto titulado "La obra de Octavio Paz. Poesía del desvelo", en el que comenta la poesía y poética del autor, en especial el libro recién publicado $A$ la orilla del mundo. En uno de los apartados, Charry Lara (2012) comenta algunos postulados de André Breton en el Primer manifiesto, mencionados por Paz, y afirma que el propósito de la unión entre el sueño y la realidad en una "suprarrealidad o realidad absoluta" es una "tendencia realmente revolucionaria del arte moderno" (p. 75). También reconoce que en lengua española el surrealismo tiene la particularidad de apelar no a la abolición de la conciencia, sino más bien al "milagro de que el hombre pueda tener conciencia de su inconsciencia. Lo que supone, como es natural, no el abandono sino la lucidez de los sueños" (p. 76). En este sentido, la expresión "conciencia del delirio" puede resumir

[...] la posición de Octavio Paz respecto al problema aludido, que a todos los poetas de la época se les ha planteado, de saber si el acto poético obedece a fenómenos irracionales o a una absoluta claridad intelectual. No una cosa ni la otra en forma exclusiva. Sino, como parecen reclamarlo estas expresiones, fruto de la inteligencia sobre el sueño es la poesía (p. 77).

Aquí no solo hay una evaluación y mayor comprensión de los postulados del movimiento surrealista, sino además el reconocimiento de su impulso renovador en la poesía contemporánea y las particularidades de la recepción de estos postulados en los poetas de lengua española. De este modo, Charry Lara demuestra a partir de este ensayo una mayor comprensión y asimilación de la poética surrealista y le asigna el papel renovador de las letras de su tiempo que antes tuvo el Romanticismo en el siglo xIx.

Años más tarde, en 1956, Charry Lara publica en Mito un ensayo titulado “Tres poetas mexicanos" en el que habla sobre la obra de Ramón López Velarde, Xavier Villaurrutia y Octavio Paz. En el apartado sobre Paz, Charry Lara reproduce su ensayo de 1951 con algunas adiciones importantes. Entre ellas, se encuentra un apartado sobre la imagen poética en términos que se acercan al surrealismo, aludiendo a reflexiones de y sobre Breton que hace Paz en El arco y la lira, recientemente publicado. Para Charry Lara (2012), en este ensayo, la imagen debe ser el "centro 
solar de toda poesía”, pues "el hombre se empeña en rasgar el misterio de sí mismo y, en este afán desesperado, la imagen poética le es un puñal ávido y penetrante” (p. 104).

Hacia el final, Charry Lara afirma que la reflexión sobre la imagen y la relación del poeta con la sociedad en El arco y la lira

[...] corresponde al desarrollo de tesis surrealistas de singular importancia. Paz las estudia con inteligencia apasionada y despierta. Analiza el programa surrealista de transformar la vida en poesía para operar, así, una revolución definitiva sobre los espíritus y la vida social, hallándolo similar al programa romántico de Federico Schlegel (p. ıоб).

La preeminencia de la imagen en el surrealismo es el desarrollo de uno de los problemas del Romanticismo. El surrealismo, entonces, ya no es solo un "Romanticismo exagerado", sino la ampliación de muchos de los problemas planteados por este último. Al respecto, Charry Lara afirma que "los surrealistas, al igual que los románticos, atacan los conceptos de objeto y sujeto" (p. 106) y se pregunta:

[...] ¿cuál será, entonces, el fin último de la imagen? $\mathrm{Al}$ reunir o acercar realidades opuestas, unifica la diversidad del mundo. Y, lo que es más importante, elimina la contradicción entre objeto y sujeto. El poeta se empeña en verificar la correspondencia de los contrarios (p. I04).

Más allá de la escritura automática, Charry Lara descubre en la teoría surrealista la función de la poesía en su tiempo, el propósito del poeta en el mundo contemporáneo: "la total recuperación de nuestra fuerza psíquica por un medio que consiste en el vertiginoso descenso al interior de nosotros mismos” (Breton, 2006, p. 116).

Ya para 1961, la lectura de De Baudelaire al surrealismo de Marcel Raymond vino a confirmar y ampliar las esperanzas de Charry Lara en los postulados surrealistas, porque "en su sentido más estrecho, el surrealismo es un método de escritura; en su sentido más amplio, una actitudfilosófica que es a la vez una mística” (Raymond,2002, p. 242). En el ensayo sobre el libro de Raymond, además de hacer entusiastas afirmaciones, Charry Lara (2012) corrige tácitamente sus primeras impresiones de los ensayos de 1940 sobre la preeminencia del inconsciente en la poética surrealista: 
El superrealismo ha de quedar indicado como una de las más asombrosas aventuras del espíritu humano. En ningún tiempo el hombre, soñador definitivo, ha soñado tanto en la poesía. [...] Es cierto que en algunos momentos se ha querido entender el superrealismo en forma bastante ingenua, exagerando el inconsciente, extremando la incoherencia y demostrando una sola habilidad negativa que apenas logra la ruptura con lo racional y lo sensible. Es verdad que se creyó con demasiada benevolencia en las virtudes del automatismo. Mas el hecho de haberse propuesto unos problemas de tan difícil solución para nuestro estado actual de prisioneros de todos los convencionalismos, de haber destrozado muchas sombras y mostrado el camino hacia una realidad que imaginamos más auténtica, nos demuestra su importancia verdadera (p. 133).

Charry Lara (2012) afirma que Raymond hace un "reconocimiento implícito a los valores esenciales de la experiencia surrealista" al describir la finalidad última de la poesía como la aprehensión de la realidad del campo claroscuro del pensamiento y de los accidentes del lenguaje (p. 134). Según esto, el poeta tiene "la misión de sobreponerse a ese dualismo" (p. 134) entre el mundo interior y el exterior. La validez del movimiento, o mejor de sus postulados, no radica en el ámbito formal de sus obras o las técnicas de composición, sino en el sustento filosófico que da a la poesía al plantearse como objeto las cuestiones últimas del ser humano, las preguntas existenciales del ser contemporáneo. Esta comprensión, y variación con respecto a los primeros trabajos, se verá aplicada en dos ensayos de esa época sobre sus modelos poéticos: Aleixandre y Cernuda.

También en 1961, Charry Lara publica un ensayo sobre Cernuda, en el que habla sobre el influjo de la poesía inglesa, la importancia de la metáfora para la generación del 27 y la influencia de la guerra civil en la obra del poeta. Charry Lara (2012) identifica su poesía como una "exploración desentrañadora del mundo", y al recordar la anécdota del poeta sobre un momento decisivo en el despertar de su instinto poético una tarde en que "las cosas se [le] aparecieron como si las viera por vez primera", reconoce que seguramente

[...] la lectura de los poetas superrealistas debió ejercer entonces, en una etapa oportuna, una influencia fértil y renovadora, que aun cuando se apagase en él después, en sus manifestaciones externas, habría de perdurarle en una íntima convicción acerca del carácter frenético y rebelde de la poesía (pp. 139-140).

La lectura de los surrealistas se convierte en un sustrato, en abono para el desarrollo de la poesía no solo de Cernuda, sino del mismo Charry Lara. No es ya un movimiento 
al que adherirse o con el que identificarse, sino una actitud filosófica ante la vida y la literatura que subyace a distintas manifestaciones escritas.

Años más tarde, en un artículo de 1968 titulado "Aleixandre y el surrealismo", Charry Lara (2012) afirma que la poesía de Aleixandre "contribuyó con su hermosa eficacia a establecer esa zona de delirio y de magia que hace posible el surgimiento de un verso. Nos situaba en un mundo en el que, con frecuencia, el sueño es asombrosamente real" (p. 222). Por otra parte, reconoce las cualidades oníricas de la poesía de Aleixandre, y aunque el mismo autor no acepte su vinculación con el movimiento, "en una cierta medida existe, innegablemente, influjo del surrealismo" (p. 223) en su obra. Esta afirmación contrasta con las que se hallan en sus ensayos de 1940. Charry Lara (2012) entra entonces a explicar la particular "conciencia de la inconsciencia" o "lucidez del sueño" en la recepción del surrealismo en los poetas de habla española; y más adelante, casi citando a Raymond, concluye: "no limitemos, entonces, el surrealismo a la escritura automática y comprendamos mejor lo que significa para el hombre esta recuperación de sus perdidas riquezas” (p. 224). Más de veinte años después de sus primeros artículos sobre Cernuda y Aleixandre, y tras numerosas lecturas y ponderación de puntos de vista, Charry Lara logra desligar las técnicas surrealistas más visibles, entender el movimiento como el último eslabón, en su tiempo, de la aventura romántica. El mismo Breton, afirma Charry Lara (2012), reconoció el "infortunio completo" de la escritura automática y, por tal razón,

\begin{abstract}
[...] que el descenso hacia el interior del espíritu no haya observado, en otros poetas, esa técnica, no autoriza para desconocer en ellos una actitud rebelde contra el largo monopolio de lo razonable y de lo verosímil y, más específicamente, su coincidencia con muchos aspectos de esa desesperada y singular hazaña por lo maravilloso: la libertad, el amor y la poesía (p. 224).
\end{abstract}

Así pues, el aprendizaje de Charry Lara sobre el surrealismo no solo tuvo efecto en sus ensayos sobre Cernuda y Aleixandre, y modificó sus juicios sobre la poesía moderna, sino que renovó su propia producción poética. Como en Cernuda, el surrealismo se convirtió en una "influencia fértil y renovadora" que persistiría "en una íntima convicción acerca del carácter frenético y rebelde de la poesía” (p. 140). Según David Jiménez (2002), en la obra de Charry Lara 
[...] no se llega a la escritura automática ni la asociación es tan libre como en el poema surrealista, pero la unidad racional del conjunto queda atenuada, borrosa y deja lugar a un relampagueo de sugerencias que el lector debe reconstruir con los datos fragmentarios que va dejando en su memoria el fluir de los versos (p. I62).

En este proceso, que culmina en su último libro Pensamientos del amante (1981), se comprueba la búsqueda, a través de la imagen y la reconciliación de los contrarios en el poema, de las respuestas a las preguntas últimas que el ser humano experimenta y la apropiación de la actitud filosófica surrealista que

[...] pretendió ser algo distinto de una retórica o de un movimiento literario. Implicaba, como es sabido, la liberación del espíritu de las mutilaciones a que lo han sometido la lógica y los convencionalismos sociales, una pretensión de desencadenar las potencias oscuras de nuestro ser, una búsqueda vertiginosa de lo intuitivo sin mancha. Su esperanza de cambiar al hombre y a la sociedad no habría podido jamás reducirse a un formulismo excluyente (Charry Lara, 2012, p. 223).

El valor del surrealismo para Charry Lara iba de la mano con el descubrimiento de estas "potencias oscuras", de las que también hablan Raymond y Breton, y de lo intuitivo y su consecuente liberación de ese "monopolio de la razón”, tan defendido por críticos como Rafael Maya. El surrealismo deja de ser un movimiento para convertirse en una tentativa que excede los límites de lo literario: recuperar la totalidad de la vida psíquica, transformar el mundo y cambiar la vida. Como hemos visto hasta aquí,

[...] en Colombia no hubo la agitación que acompañó a los movimientos y grupos de vanguardia en el resto de América y en Europa. El medio intelectual que propició sus audacias y estimuló sus rupturas con las tradiciones literarias dominantes estaba conformado por un puñado de amigos y contertulios (Luis Tejada, Ricardo Rendón, León de Greiff, a cuyos nombres habría que agregar los de los españoles Juan José Pérez Domenech y Ramón Vinyes), vinculados por ciertos nexos ideológicos, tanto políticos como estéticos, pero sin las condiciones que por lo regular aseguraron en otras partes la difusión y resonancia de cada movimiento (Jiménez, 2002, p. 100).

No obstante, a lo largo de este artículo se ha podido comprobar la importancia que tuvo el movimiento surrealista para la modernización de la poesía en el país. El surrealismo, o mejor, la lectura que hicieron de él los poetas hispanoamericanos fue imprescindible para dar fundamento ético a los procesos de autonomización que 
estaba viviendo la literatura latinoamericana luego del modernismo. Ante la pérdida de un nexo directo con la sociedad, o de una función socialmente reconocida, la poesía encuentra un sustento filosófico, artístico e incluso, en algunos casos, político, que la eleva a un plano de transformación espiritual.

La lectura del surrealismo como actitud espiritual — que predominó e hizo eco en Charry Lara - produjo una nueva concepción de la poesía que rompió los moldes de la racionalidad, la sintaxis, la belleza y el orden establecido, y acercó el lenguaje al mundo del sueño. La poesía, gracias a los aportes teóricos surrealistas, escapó de los laberintos de la poesía pura, ajena a cualquier sentimiento o experiencia vital, y se convirtió para los poetas hispanoamericanos como Charry Lara en una forma de conocimiento, una revolución del espíritu y quizá la única forma de salvación y liberación del ser humano.

\section{Referencias bibliográficas}

Ardila Ariza,J. (2013). Vanguardia y antivanguardia en la crítica y en las publicaciones culturales colombianas de los años veinte. Bogotá: Universidad Nacional de Colombia.

Bejarano, J. (1982). “La economía”. En Manual de Historia de Colombia Tomo III (pp. 15-79). Bogotá: Procultura.

Breton, A. (2006). Manifiestos del surrealismo. La Plata: Terramar.

Charry Lara, F. (1986). Llama de amor viva. Bogotá: Procultura.

Charry Lara, F. (2012). Vida y obra de Fernando Charry Lara. Tomo II: Obra critica 1940-1986. Bogotá: Instituto Caro y Cuervo.

García, A. (1941). De Valencia a Carranza. El Tiempo (24 de agosto), pp. 1-2.

Gutiérrez Girardot, R. (2011). Ensayos de literatura colombiana. Medellín: Unalua.

Holguín, A. (1944). El poeta de 1944. Fernando Charry Lara. Lecturas Dominicales. El Tiempo (31 de diciembre), p. 1.

Jaramillo Uribe, J. El proceso de la educación del Virreinato a la época contemporánea. En Manual de Historia de Colombia Tomo III (pp. 247-339). Bogotá: Procultura.

Jiménez, D. (1992). Historia de la crítica literaria en Colombia. Bogotá: Universidad Nacional de Colombia.

Jiménez, D. (2002). Poesía y canon: los poetas como criticos en la formación del canon de la poesía moderna en Colombia 1920-1950. Bogotá: Norma.

Raymond, M. (2002). De Baudelaire al surrealismo. México, D.F.: Fondo de Cultura Económica.

Romero, A. (1985). Las palabras están en situación. Un estudio de la poesía colombiana de 1940 a 1960. Bogotá: Procultura.

Tejada, L. (1977). Un poeta nuevo. En Gotas de tinta (pp. 158-160). Bogotá: Instituto Colombiano de Cultura. 